\title{
Impact of SARS-CoV-2 on pregnancy outcomes (Review)
}

\author{
PANAGIOTIS TSIKOURAS ${ }^{1}$, VASILIKI KOURTI $^{1}$, AGGELIKI GEREDE $^{1}$, ELENI KIOSSE $^{1}$, \\ MARIA PANOPOULOU $^{2}$, STEFANOS ZERVOUDIS ${ }^{3}$, ANASTASIA BOTHOU ${ }^{1}$, \\ GEORGE IATRAKIS $^{3}$, FOTINI GAITATZI ${ }^{1}$, XANTHI VATSIDOU ${ }^{1}$, ANNA CHALKIDOU ${ }^{1}$, \\ KONSTANTINOS NIKOLETTOS ${ }^{1}$, ALEXIS ALEXIOU ${ }^{1}$, PANAGIOTIS PEITSIDIS ${ }^{1}$, \\ MARIA LAMBROPOULOU ${ }^{4}$, SPYRIDON MICHALOPOULOS ${ }^{1}$, \\ NIKOLAOS NIKOLETTOS ${ }^{1}$ and PETROS RAFAILIDIS ${ }^{5}$
}

\begin{abstract}
${ }^{1}$ Department of Obstetrics and Gynecology, Democritus University of Thrace; ${ }^{2}$ Laboratory of Clinical Microbiology, Medical School, Democritus University of Thrace, 68100 Alexandroupolis; ${ }^{3}$ Technological Educational Institute of Athens and Rea Maternity Hospital, 17564 Athens; ${ }^{4}$ Department of Histology and Embryology, Medical School, Democritus University of Thrace; ${ }^{5}$ Second Department of Internal Medicine, University Hospital of Alexandroupolis, Democritus University of Thrace, 68100 Alexandroupolis, Greece
\end{abstract}

Received August 17,2021; Accepted October 25, 2021

DOI: $10.3892 / \mathrm{mi} .2021 .19$

\begin{abstract}
The impact of the pandemic outbreak associated with coronavirus 2019 disease (COVID-19) on pregnant women is of interest to obstetricians and gynecologists due to the vulnerability of this target group. In pregnant women and their infants, an exceptional clinical management is warranted. Current epidemiological findings provide information regarding the effects of severe acute respiratory syndrome coronavirus 2 (SARS-CoV-2) on pregnant patients and potential adverse perinatal outcomes. Overall, these findings are a strong indication that an increased antenatal surveillance for pregnant patients infected with COVID-19 is warranted. The aim of the present narrative review was to summarize the data obtained to date regarding the health of women during pregnancy, as well as that of the fetus associated with the risk of severe infection due to COVID-19. The present review aimed to provide further insight into the effects of this pandemic on pregnancy, also providing the experience of the authors on this matter as an example.
\end{abstract}

\section{Contents}

1. Introduction

2. Comparison of SARS-CoV-2, SARS-CoV and MERS-CoV in terms of genome, transmission and incubation period

Correspondence to: Professor Panagiotis Tsikouras, Department of Obstetrics and Gynecology, Democritus University of Thrace, Dragana, 68100 Alexandroupolis, Greece

E-mail: tsikouraspanagiotis@gmail.com

Key words: SARS-CoV-2, first trimester pregnancy, second trimester pregnancy, third trimester pregnancy
3. Incubation period

4. Diagnostic tests

5. Immunology of pregnancy and COVID-19

6. First trimester: Early pregnancy

7. Second and third trimester: Late pregnancy

8. Obstetric and postpartum management

9. The authors' experience

10. Conclusion and future perspectives

\section{Introduction}

The current pneumonia pandemic outbreak caused by severe acute respiratory syndrome (SARS) coronavirus 2 (SARS-CoV-2), originated from Wuhan (China) in December, 2019 and since then, has spread worldwide, with a basic reproduction number $\left(\mathrm{R}_{0}\right)$ of 2-2.5 (1-3). The majority (64\%) of cases have been between the ages of 25-64 years and as regards sex, $\sim 47 \%$ of cases have been female $(4,5)$. According to these current statistics, $>50 \%$ of patients with COVID-19 belong to the reproductive age group. However, limited data are available for pregnant women. Moreover, there are a number of unanswered questions regarding the impact of COVID-19 on pregnancy, such as its association with complications during pregnancy, the management of infected pregnant women, vertical maternal-fetal transmission and the effects of COVID-9 postpartum (6,7). The present review summarizes the current data related to these prevailing questions, and also provides information on pregnancy outcomes associated with related and highly pathogenic coronaviruses, namely SARS and Middle East respiratory syndrome coronavirus (MERS-CoV)]. The authors elected to perform a narrative review approach as opposed to systematic one, as this was considered more appropriate regarding the relatively recent pandemic outbreak. The authors also present their own experience from the University General Hospital of Alexandroupolis. 


\section{Comparison of SARS-CoV-2,SARS-CoV and MERS-CoV in terms of genome, transmission and incubation period}

Coronaviruses belong to the Coronoviridae family of the order Nidovirales and constitute the Orthocoronavirinae subfamily. They are divided into four genera: Alphacoronavirus, Betacoronavirus, Gammacoronavirus and Deltacoronavirus. SARS-CoV, MERS-CoV and SARS-CoV-2 all belong to the Betacoronavirus genera (8).

Coronaviruses are enveloped, spherical viruses with a crown-like appearance under an electron microscope, as a result of the spike glycoproteins on the virion surface. Their genome is organized in a positive-sense, single-stranded RNA of $\sim 30 \mathrm{~kb}$ in size $(9,10)$. Unlike the majority of eukaryotic mRNAs, coronavirus genomes are very large and contain multiple open reading frames (ORFs), a $5^{\prime}$ cap structure and a 3 ' poly (A) tail. At the 5 ' end, there is a leading sequence followed by the $5^{\prime}$ untranslated region (5'UTR) and the initiation codon for ORF1, which encodes a number of non-structural proteins important for replication, and accounts for the two-thirds of the whole genome. The main structural proteins, spike (S), envelope (E), membrane (M) and nucleocapsid (N), as well as the accessory proteins, are encoded within the one-third of the genome near the 3 'end $(11,12)$.

As regards the structural proteins, S,E,M and N, all are involved in the formation of the viral particle, but also seem to play a role in other aspects of the replication cycle. Spike protein (S) consists of a transmembrane domain (TM), a short intracellular C-terminal segment and a large N-terminal segment with two subunits (S1 and S2), which are responsible for receptor binding and cell-to-cell fusion, respectively $(13,14)$. The $\mathrm{N}$ protein binds the RNA of the virus and seems to play a critical role in the transcription and translation of the virus (13). The M protein is involved in viral assembly and, along with the $\mathrm{E}$ protein, mediates the envelop construction and viral budding (13-16).

The genome size of SARS-CoV-2 is $\sim 29.9 \mathrm{~kb}$ similar to the 29.75 and $30.11 \mathrm{~kb}$ genomes of SARS-CoV and MERS-CoV, respectively. Previous studies have confirmed that SARS-CoV-2 shares a $79.5 \%$ sequence identity with SARS-CoV, which are both lineage B Betacoronaviruses, whereas it only has 50\% similarity with MERS-CoV, a lineage C Betacoronavirus, indicating a closer association between SARS-CoV-2 and SARS-CoV (9-16). When comparing the genome organization of these two viruses, the main differences are found in ORF3b, ORF8 and spike S1 (16). In detail, there is a major difference in the length of the ORF3b between the two viruses. SARS-CoV-2 with a longer ORF3b appears to have a greater ability to suppress interferon (IFN) activity (17). As regards ORF8b, an accessory protein which appears to be poorly conserved among coronaviruses, Shi et al (18) indicated that SARS-CoV ORF8Bb can activate the NLR family pyrin domain containing 3 (NLRP3) inflammasome and trigger stress pathways, whereas SARS-CoV-2 ORF8 does not yet contain a known functional domain (16-18). As already mentioned, Spike protein mediates the entry of the virus into host cells. The S1 subunit includes the receptor binding domain (RBD), which is responsible for binding to the host cell receptor. The host cell receptor for MERS-CoV is dipeptyl peptidase 4 (DPP4 or CD26), while the receptor for both SARS-CoV and
SARS-CoV-2 is angiotensin-converting enzyme 2 (ACE2), a finding supported by the high homology rate between their $S$ proteins. After binding to their receptors, $S$ proteins undergo cleavage by proteases of the host to permit fusion and both SARS-CoV and SARS-CoV-2 have been shown to mainly use the serine protease, transmembrane serine protease 2 (TMPRSS2) and the cysteine proteases, cathepsin B and L (9). Despite the similarities with SARS-CoV, a distinctive characteristic of SARS-CoV-2 is the furin cleavage site (motif RRxR) at the S1-S2 boundary that may contribute to high affinity binding with the host cell receptor, leading to efficient infection, overcoming the species barrier and high transmissibility from human-to-human. Although MERS-CoV has a similar motif ( $\mathrm{RxxR})$ at the S1-S2 boundary, the insertion of the second arginine in SARS-CoV-2 S1-S2 site appears to enable a more sufficient cleavage from furin-like enzymes (19-22).

Transmissibility, the ability of a pathogen to spread, can be measured by the basic reproductive number $\left(\mathrm{R}_{0}\right)$, which represents the cases directly generated by one infected individual in a population where all individuals are susceptible to infection. The average $\mathrm{R}_{0}$ for SARS-CoV-2 is estimated to be 2.5 , higher than the $\mathrm{R}_{0}$ of SARS-CoV and MERS-CoV. Specifically, the $\mathrm{R}_{0}$ of SARS-CoV was estimated to be $2-3$ before and 1.1 following the introduction of the public measures in 2003, while for MERS-CoV, the $\mathrm{R}_{0}$ was $<1$ (9-22). SARS-CoV-2 mainly causes cluster transmission between members of a family, while the human-to-human transmission of SARS-CoV and MERS-CoV mostly occurs through nosocomial transmission and only at a rate of $22-39$ and $13-21 \%$ between family members, respectively $(22,23)$. This may be due to the fact that the SARS-CoV and MERS-CoV viral load peaks occur after first week of illness, in contrast to SARS-CoV-2, whose viral load peaks during the first week (24). SARS-CoV can be transmitted by direct person-to-person contact through air droplets and indirect contact through contaminated surfaces, while previous studies have indicated airborne transmission as well (9-25). MERS-CoV can be acquired through contact with both infected dromedary camels, which serve as a host reservoir for the virus and occasionally by infected patients (9). In addition, MERS-CoV has been isolated from environmental objects, mainly in healthcare facilities, underlying the risk of fomite transmission (26). Evidence ofthe fecal excretion of both SARS-CoV and MERS-CoV, as long as prolonged viability permits under various conditions, indicates the fecal-oral transmission as a possible route for viral transmission (27).

Similarly, the main pathway of transmission of SARS-CoV-2 is direct human-to-human transmission through contact routes or air droplets. Direct droplet transmission will occur when the uninfected individuals closer than $1 \mathrm{~m}$ to the infected individual, as droplets can travel a distance of $\sim 6 \mathrm{ft}$ (28). Furthermore, studies have demonstrated that SARS-CoV-2 can remain viable for a long period of time in the environment, thus suggesting other methods of transmission similar to SARS-CoV, such asairborne transmission or fomite transmission $(29,30)$. However, the greater affinity of SARS-CoV-2 compared with that ofSARS-CoV for the ACE receptor, as aforementioned, not only enables SARS-CoV-2 to be a much more virulent virus, but justifies its potential spread via the fecal-oral route, as regards the expression of ACE receptor 
Table I. Epidemiological characteristics of SARS-CoV-2, SARS-CoV and MERS-CoV.

\begin{tabular}{|c|c|c|c|}
\hline Characteristic & SARS-CoV-2 & SARS-CoV & MERS-CoV \\
\hline Genome size $(\mathrm{kb})$ & 29.9 & 29.75 & 30.11 \\
\hline Family & Coronaviridae & Coronaviridae & Coronaviridae \\
\hline Genus & Betacoronavirus & Betacoronavirus & Betacoronavirus \\
\hline Lineage & $\mathrm{B}$ & $\mathrm{B}$ & $\mathrm{C}$ \\
\hline Host cell receptor & ACE2 & ACE2 & DPP4 \\
\hline Furin cleavage site & Yes (RRxR) & No & Yes (RxxR) \\
\hline Viral load peak & At the first week of illness & After the first week of illness & After the first week of illness \\
\hline $\mathrm{R}_{0}$ & 2.5 & $2-3$ & $<1$ \\
\hline Transmission scenario & Mainly cluster transmission & $\begin{array}{l}\text { Mainly nosocomial } \\
\text { transmission }\end{array}$ & Mainly nosocomial transmission \\
\hline Human-to-human transmission & $\begin{array}{l}\text { Through air droplets, contact } \\
\text { routes, fomites and possible } \\
\text { through airborne and } \\
\text { maternal-fetal transmission }\end{array}$ & $\begin{array}{l}\text { Through air droplets, } \\
\text { fomites, airborne and } \\
\text { fecal-oral transmission }\end{array}$ & $\begin{array}{l}\text { Occasionally through } \\
\text { air droplets, contact } \\
\text { routes and fomites }\end{array}$ \\
\hline Median incubation period & $\begin{array}{l}\text { Current estimates } \\
\text { indicate } 5-6 \text { days }\end{array}$ & 4 days $(95 \%$ CI, 3.6-4.4) & 5.2 days $(95 \%$ CI, 1.9-14.7) \\
\hline
\end{tabular}

${ }^{a}$ The data for the CI values shown in the table were obtained from previous studies $(43,44)$. SARS-CoV-2, severe acute respiratory syndrome coronavirus 2; MERS-CoV, Middle East respiratory syndrome coronavirus; $\mathrm{R}_{0}$, basic reproduction number.

in the intestine (23-30). There is evidence demonstrating detectable RNA levels in both feces and blood, increasing the possibility of fecal-oral and blood transmission (31). Additionally, there is evidence of the transplacental transmission of SARS-CoV-2 during the last weeks of pregnancy, causing placental inflammation; however, further evidence needs tobe provided on how the virus can be transmitted from the mother to the fetus (32). Transmission via ocular surfaces should not be ignored, since there is evidence of SARS-CoV predominantly being transmitted through contact with mucous membranes and incidents of patients exhibiting conjunctivitis prior to the onset of COVID-19 (31-33).

\section{Incubation period}

A previous systematic review of acute respiratory viral infections demonstrated that the median incubation period of SARS-associated coronaviruses was 4 days [95\% confidence interval (CI), 3.6-4.4] (34). As regards the median incubation period of MERS-CoV, Memish et al (35) indicated that although this was 5.2 days (95\% CI, 1.9-14.7), a longer incubation time is likely to be observed among immunocompromised patients. Although the incubation period of SARS-CoV-2 has not yet been established, it has been indicated that there is no significant difference between the incubation times of the three coronaviruses (36). In a previous study, from an analysis that included data from 181 cases with confirmed COVID-19 infection outside Hubei province, it was estimated that the median incubation time was 5.1 days (95\% CI, 4.5-5.8 days) (37). Another meta-analysis examining published results between January 24 and April 2, 2020 revealed that the average incubation time was 5.08 days (95\% CI, 4.77-5.39) (38). An additional meta-analysis on 22,595 patients indicated that the overall pooled average incubation period was 5.7 days $(95 \% \mathrm{CI}$, 5.1-6.4), which is slightly higher than that of SARS-CoV and MERS-CoV. The same analysis estimated a longer incubation period of up to 6.1 days (95\% CI, 5.34-6.94) of SARS-CoV-2 in China compared with other countries (39). The indicative epidemiological characteristics of each coronavirus are shown in Table I.

\section{Diagnostic tests}

Sensitivity, specificity and accuracy determine the reliability of a diagnostic test (40). There are two main categories of diagnostic tests for COVID-19; the nucleotide acid-based methods, which include reverse transcription-quantitative polymerase chain reaction (RT-qPCR) and antibody-based methods, such as enzyme-linked immunosorbent assay (ELISA), colloidal gold immunochromatographic assay (GICA) and chemiluminescence immunoassay (CLIA) (41).

RT-qPCR remains the gold standard for the diagnosis of COVID-19 using mainly nasopharyngeal swabs and sputum, as well as other upper respiratory tract specimens, such as oropharyngeal swabs and saliva (42). The need for the rapid diagnosis of COVID-19 led to the development of other promising technologies for DNA amplification, such as reverse transcription loop-mediated isothermal amplification (RT-LAMP) and clustered regularly interspaced short palindromic repeats (CRISPR)-based methods which are faster, cost-effective technologies and appear to have a high sensitivity and specificity as well (40-49). The limitations in nucleotide acid-based methods, such as the long turnaround time and the specific equipment needed, as well as the number of false-negative results, led to the supporting role of antibody-based methods for the detection of SARS-CoV-2. 
Rapid test sensitivity
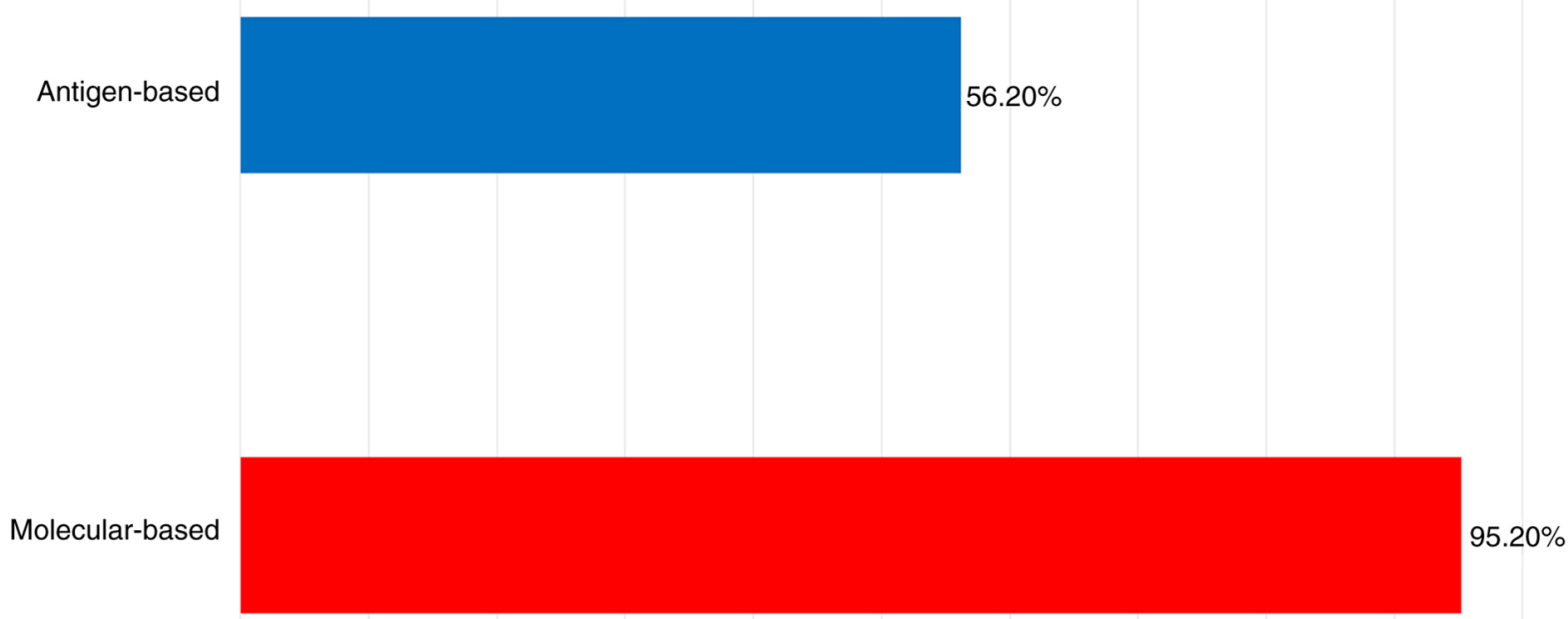

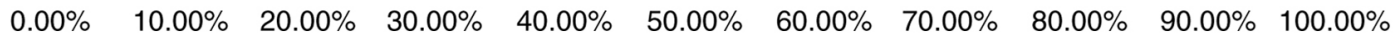

Figure 1. Accuracy of diagnostic rapid tests for the diagnosis of SARS-CoV-2 infection. SARS-CoV-2, severe acute respiratory syndrome coronavirus 2 . The data shown in the figure were obtained from a previous study (125).

The efficiency and simplicity of ELISA and CLIA render these methods suitable for first-line screening. The accuracy of various tests for the detection of SARS-CoV-2 is presented in Figs. 1 and 2, and Table II (40-49).

\section{Immunology of pregnancy and COVID-19}

Pregnant women during this pandemic represent a susceptible group due to their altered physiological physiology, immunology and pathology mechanisms, not only pre-but also post-partum. Pregnancy alters the immunological environment, initially to a Th1 phenotype during the first trimester, and then to Th2 by the second trimester, and finally again polarizes toward to a Th1 phenotype at the end of third trimester. Concomitant with the initiation of parturition, cytokines produced by Th1 lymphocytes are pro-inflammatory and microbicidal, and consist by interferon- $\gamma$ and certain interleukin (IL) proteins (IL-1a, IL-1b, IL-6 and IL-12). By contrast, Th2 cytokines are anti-inflammatory and include IL-4, IL-10 and IL-13, and transforming growth factor (TGF)-b (50). On account of this normal shift to a Th2-dominant immune system which protects the fetus, the debility of Th1 renders the mother vulnerable to viral infections, which are more effectively contained by the Th1 system (50). The contributions of the immune system to pregnancy and fetal development provide important insight into the pathogenesis underlying the infection of pregnant women with COVID-19, as well as into possible targets for therapy. In non-pregnant patients infected with SARS-Cov-2, the activation of both Th1 and Th2 immunity has been observed, culminating in the presence of IFN- $\gamma$ and IL-1b, in addition to IL-4 and IL-10 $(44,45)$. In addition, in plasma from COVID-19-positive patients, elevated levels of IL-6 (a predominantly Th1 response cytokine) are associated with an increased risk of mortality and severe pneumonia (44). Thus, this physical shift to a Th2-dominant immunology environment and the lack of Th1, which affects the period from week 13 to 27 of pregnancy, suggests that these early adaptive immune responses may be predictive of milder disease severity in pregnant women. Indeed, the intense inflammatory response has been reported as the cause of severe COVID-19 infection $(7,44)$. Therefore, the relative immunosuppression in pregnancy may be the reason as to why numerous pregnant women do not develop severe respiratory syndrome. Contrary to this theory, the American College of Obstetricians and Gynecologists $(5,6)$ made a comparison between pregnant and non-pregnant women with COVID-19 and concluded that pregnant women are at an increased risk of developing severe symptomatology. Thus, they have a higher possibility of being admitted to the intensive care unit (ICU; 1.5 vs. $0.9 \%$ ) and may also have a greater need for mechanical ventilation ( 0.5 vs. $0.3 \%)$. The vulnerability of pregnant women to COVID-19 has also been supported by Dashraath et al, who also reported similar findings (45). Namely, they observed symptoms similar to non-pregnant patients; the predominant symptoms of COVID-19 in pregnant patients were fever (prevailing symptom), cough, dyspnea and lymphopenia and they also reported of other cohort studies in patients with other infections where no increased risks of congenital anomalies have been shown. However, the reported miscarriage, intrauterine growth restriction and pre-term birth as fetal complications 


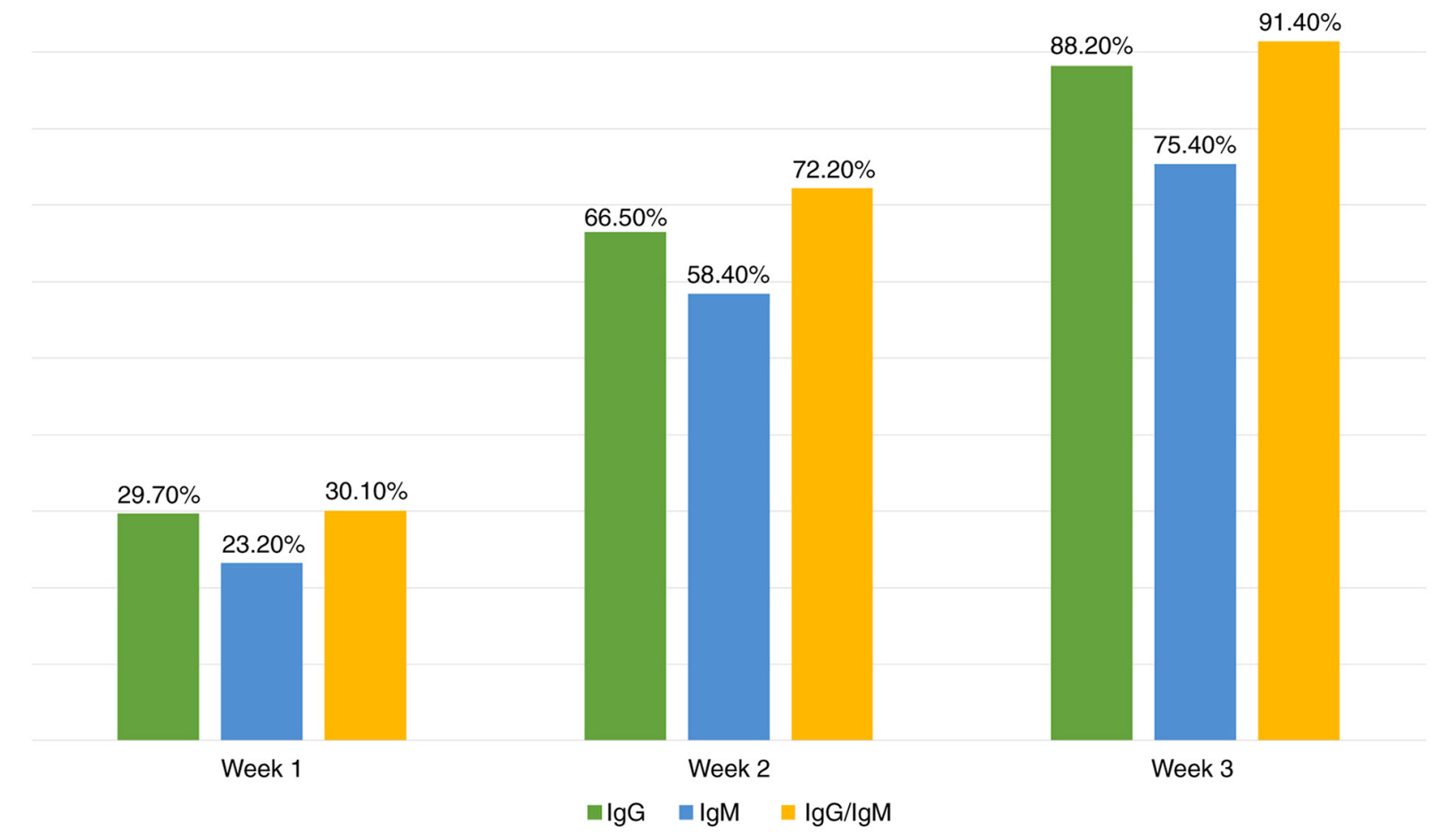

Figure 2. Accuracy of diagnostic antibody tests for the diagnosis of SARS-CoV-2 infection. SARS-CoV-2, severe acute respiratory syndrome coronavirus 2. The data shown in the figure were obtained from a previous study (126).

associated with COVID-19, appear to be less severe compared with those associated with SARS and MERS (46-49,51-59).

\section{First trimester: Early pregnancy}

Placental development during the 1st trimester is crucial, due to vulnerability to a number of pre- and post-partum complications (46,60-67). This observation has been extensively investigated by a notable number of research groups, as immunological disturbances are crucial in mediating a successful pregnancy, from implantation to parturition. One such example of the importance of the first trimester, is maternal pyrexia, a disorder that is related to hyperthermic injury to fetal neurons (67). There is a theoretical risk of complications, similar to that observed in SARS, as the ACE2 receptor is widely expressed in the placenta (45-47) with a similar receptor-binding domain structure between SARS-CoV and SARS-CoV-2. This also sets the hypothesis of vertical transmission (68). In line with previous research (69), SARS-CoV and SARS-CoV-2 share a common binding structure genotype. Crucial data on maternal and fetal outcomes could be raised by the histopathological examination of the placenta in order to confirm COVID-19 binding to placental ACE-2 receptors. Samples of placentas positive for SARS-CoV-2 have exhibited anincreased deposition of immune complexes, such as fibrin and lymphocytes. In particular, in the subchorial space, the infiltration of monocytes and neutrophils has been identified (48). Placental and umbilical cord infiltration was also identified with virological findings in nine cases of women infected with SARS-CoV-2 during the first trimester of gestation, where severe hypertension, pre-eclampsia and coagulopathy was reported (52). Evidence of placental hyperfusion defects in maternal vessels and oxygenation in the intervillous space has also been observed, affecting perinatal outcomes. All these thus far suggest pre-eclampsia, where typically, vascular villous lesions including fibrin deposition within and around the villi and infarcts have been reported. The aforementioned placental pathology associated with SARS-CoV-2 infection, has also been reported in placentas from SARS-CoV-2 and MERS-positive patients, where placental infiltration has been shown to lead to acute and chronic placental insufficiency associated with intrauterine growth restriction or the miscarriage of affected cases during pregnancy and pre-term delivery $(67,70)$. Therefore, in order to predict the possible COVID-19-related complications during the first trimester, examining the placental virological findings is of utmost importance. Taking into consideration that SARS affects $4 / 7$ pregnant women in first trimester, leading to miscarriage, and at the same time the common genotypes between SARS-CoV and SARS-CoV-2, the need for the provision of fetal monitoring, including a serial ultrasound examination, of women with COVID-19 may be of utmost significance (45).

\section{Second and third trimester: Late pregnancy}

As observed from the SARS data and from the available SARS-CoV-2 data, there is an increased risk of pregnant women being infected with COVID-19 (55-57,64). Early pregnancy data and matched control data on affected pregnant women are required to estimate the course of infection over the following trimesters. An infected placenta, as supported by virological findings from women (52) with ongoing pregnancy, 
Table II. Accuracy of diagnostic techniques for the diagnosis of SARS-CoV-2 infection.

Diagnostic test

(Refs.) Reverse

transcription-quantitative

polymerase chain reaction

(RT- qPCR) (46)

Sensitivity (Refs.)

73.3-97.2\% (respiratory tract samples)

Specificity (Refs.)

90-100\%

$0-24.1 \%$ (other specimens)

60.2-97.9\% (PCR protocol) (44)

(depending on

sample type) (44)

\begin{tabular}{|c|c|c|c|c|}
\hline Antibody tests (126) & 1st week & 2nd week & 3rd week & \\
\hline $\operatorname{IgG}$ & $\begin{array}{l}29.7 \% \\
(95 \% \text { CI, 22.1-38.6\%) }\end{array}$ & $\begin{array}{l}66.5 \% \\
(95 \% \text { CI, } 57.9-74.2 \%)\end{array}$ & $\begin{array}{l}88.2 \% \\
(95 \% \text { CI, 83.5-91.8\%) }\end{array}$ & $\begin{array}{l}99.1 \% \\
(95 \% \text { CI, } 98.3-99.6 \%)\end{array}$ \\
\hline $\operatorname{IgM}$ & $\begin{array}{l}23.2 \% \\
(95 \% \text { CI, } 14.9-34.2 \%)\end{array}$ & $\begin{array}{l}58.4 \% \\
(95 \% \text { CI, } 45.5-70.3 \%)\end{array}$ & $\begin{array}{l}75.4 \% \\
(95 \% \text { CI, 64.3-83.8\%) }\end{array}$ & $\begin{array}{l}98.7 \% \\
(95 \% \text { CI, } 97.4-99.3 \%)\end{array}$ \\
\hline $\operatorname{IgG} / \operatorname{IgM}$ & $\begin{array}{l}30.1 \% \\
(95 \% \text { CI, } 21.4-40.7 \%)\end{array}$ & $\begin{array}{l}72.2 \% \\
(95 \% \text { CI, 63.5-79.5) }\end{array}$ & $\begin{array}{l}91.4 \% \\
(95 \% \text { CI, 87-94.4\%) }\end{array}$ & $\begin{array}{l}98.7 \% \\
(95 \% \text { CI, } 97.2-99.4 \%)\end{array}$ \\
\hline Rapid tests (125) & \multirow{2}{*}{\multicolumn{3}{|c|}{$95.2 \%(95 \%$ CI, 86.7-98.3\%) }} & \\
\hline Molecular-based tests (126) & & & & $\begin{array}{c}98.9 \% \\
(95 \% \text { CI, } 97.3-99.5 \%)\end{array}$ \\
\hline Antigen-based tests (126) & \multicolumn{3}{|c|}{$56.2 \%$ (95\% CI, 29.5-79.8\%) } & $\begin{array}{c}99.5 \% \\
(95 \% \text { CI, 98.1-99.9\%) }\end{array}$ \\
\hline
\end{tabular}

SARS-CoV-2, severe acute respiratory syndrome coronavirus 2 .

leads to an acute and chronic pathology, particularly in the placenta and umbilical cord, and aggravates the respiratory system due to increased maternal oxygen demands from the heightened metabolism; thus, COVID-19 infection could lead to physiological dyspnea. Dyspnea and shortness of breath accompanied by fever are the commonest symptoms in pregnant women (gestational age, $>25$ weeks). Oftentimes, it is challenging to differentiate between physiological dyspnea in pregnancy from COVID-19-related symptoms (70-74). As with non-pregnant women, pregnant women infected with SARS-CoV-2 present an extended range of symptoms, from mild to severe, upon admission to the hospital; these include pneumonia with or without acute respiratory distress syndrome (ARDS), renal failure and multi-organ dysfunction. A significant rate of asymptomatic and moderately-infected pregnant woman with COVID-19 has also been reported, while $16 \%$ of pregnant women have been found to have no symptoms at all (64). Notably, asymptomatic pregnant women are not at a high risk of developing severe morbidity and mortality from COVID-19 infection. However, changes to the cardiorespiratory and immune systems during pregnancy increase the susceptibility of a woman to severe infection and hypoxic compromise. Indeed, some studies have reported clinical cases that confirm this outcome and concern that pregnant women may be more susceptible to COVID-19 infection. The state of compensated respiratory alkalosis with metabolic acidosis renders women vulnerable to respiratory diseases, such as COVID-19. Ronnje et al (65) reported the case of a 26-year-old woman who was 32 weeks pregnant, who presented with a nine-day history of typical COVID-19 symptoms, such as fever, shortness of breath, dry cough, myalgia and abdominal pain. Her clinical condition escalated rapidly, leading to liver and coagulation malfunction. Recovery was observed following a cesarean section, which was performed as an emergency in order to improve the clinical status of the woman. The study by Shanes et al (66) reported that the placental pathological findings from 16 SARS-CoV-2-positive pregnant women revealed a hypercoagulable state and intense systemic inflammation. In another systemic review, in which data from 1,316 pregnant women were included, it was concluded that pneumonia was the most common COVID-19 disease manifestation, with bilateral infiltration and ground-glass opacity as the main findings in the computed tomography scan (69). These are also the main radiological findings according to $\mathrm{Wu}$ et al (58). The clinical status of pneumonia in women infected with SARS-COV-2 is followed by pre-term birth, miscarriage, fetal growth restriction and pre-eclampsia, while $1 / 3$ women are admitted to the ICU (51). COVID-19 associated with respiratory insufficiency in late pregnancies certainly creates a complex clinical scenario. Pregnancy causes a reduction in pulmonary and end-expiratory volume, functional residual capacity and residual volume due to diaphragmatic splinting by the gravid uterus, leading to decreased total lung capacity at term and an inability for the effective clearance of pulmonary secretions. As COVID-19 pneumonia escalates from focal to the diffuse bilateral consolidation of lung parenchyma, pregnant women are more vulnerable to hypoxemic respiratory failure, considering the pulmonary changes described above (75). Furthermore, both venous and arterial thromboembolism are prevalent through the second and third trimester in pregnant women diagnosed with COVID-19, not only due to excessive inflammation and hypoxia, but also as a result of diffuse intravascular coagulation. Considering that only $1 \%$ of women in the third trimester have normal d-dimer levels based on conventional thresholds, such pregnant patients may be at a high risk of developing thrombosis and thromboembolic disorders when infected with COVID-19 (50,76-79). Thrombocytopenia and liver function abnormalities (65), both of which are complications of 
COVID-19, are also associated with pre-eclampsia with severe symptoms. Ramlakhan et al (53) also described a rapidly worsening maternal status with the ultimate diagnosis of cardiomyopathy in pregnant women with certain risk factors, such as obesity and an advanced maternal age. The aforementioned studies reported higher risks of pregnancy-related complications, including pre-eclampsia and pre-term delivery as the main outcomes, in normal and high-risk pregnancies. Of note, higher rates of cesarean delivery have been reported, while as it has been suggested, the cesarean section improves the clinical status of woman with complications exacerbated by COVID-19. It would appear that a number of the cesarean section procedures were performed for the mother's best interests, due to concern for maternal respiratory function $(61,62)$.

\section{Obstetric and postpartum management}

Thus far, pregnant patients with COVID-19 have almost invariably delivered their babies by cesarean section and frequently before term gestation. However, authorities and professional societies, such as the Italian Health Council, the English Royal College of Obstetricians and Gynaecologists, and the Society for Maternal-Fetal Medicine, have taken a stance that COVID-19 is not a contraindication to vaginal delivery. According to recent data from an Italian study, a vaginal delivery rate of $57.1 \%$ was reported (64), while these high rates of cesarean section do not seem to be representative of women who have mild to moderate disease. Obstetric surgery is an indication for pregnant women with pneumonia due to COVID-19 infection, while it is beneficial to the rehabilitation of maternal respiratory malfunction (70-73,80-96). A previous retrospective analysis in Wuhan during the COVID-19 pandemic performed by Liao et al (97) revealed no significant difference in postpartum hemorrhage and perineal resection rates between SARS-CoV-2-positive and -negative pregnant women. In the same study, no evidence of vertical transmission was reported, while all neonates delivered by pregnant women infected with SARS-Cov-2 tested negative for the infection (97). However, to date, to the best of our knowledge, there are no data available to support the recommendation of either vaginal delivery or cesarean section in order to reduce the risk of transmission to the neonate $(61,70)$. Diabetic patients are associated with a higher intrapartum risk of transmission (51-54). With reference to breastfeeding, in a mother with COVID-19, the close contact between the mother and the infant appears to be the main risk factor of transmission through infective airborne droplets (81-82,94-96). Breast milk has not been found to exhibit any viral presence $(47-49,59)$ and according to current data, the potential risks of transmission of the virus through breast milk do not outweigh the benefits of breastfeeding. However, wearing a facemask while breastfeeding and applying strict hand hygiene before touching the infant is required. Hitherto, human milk is not considered a vehicle of COVID-19 transmission; thus, there is no need for its pasteurization and it can be also given to the baby using a breast pump, thus avoiding physical contact in the event of the COVID-19 infection of the mother $(82,83,94)$. Undoubtedly, the separation between mother and neonate combined with social isolation increases levels of anxiety and depression (98-109). To control the risk of developing postpartum depression, healthcare providers should pay closer attention to maternal mental health by providing sufficient supporting services (110-112).

SARS-CoV-2 is a highly contagious virus, particularly the Brazilian and South African mutations. Governments and the scientific community are facing a challenge as data on COVID-19 are still accumulating and for specific groups, such as immunocompromised individuals, the available data remain insufficient.

\section{The authors' experience}

According to preliminary results obtained by the authors, during the period from June, 2020 until January, 2021, 14 cases of pregnant women infected with COVID-19 noted. The women had mild symptoms and diagnosis was performed based on RT-qPCR tests of nasopharyngeal swabs during the third trimester. The clinicopathological data for all patient samples used in the present study are provided in Table III. The pregnant women who participated in the study provided written informed consent in the majority of cases, and oral consent in emergency cases, indicating that they agreed to the use of their samples for scientific research. Participants provide a document proving that patient consent for participation was obtained at the time of the study. Ethical approval for the study was provided by the Ethics Committee of the University Hospital in Alexandroupolis, Democritus University of Thrace (Alexandroupolis, Greece; reference no. 42398/07/10/21). For the procedure of RT-qPCR, $8 \mu$ from each RNA extraction sample was used and the master mix buffer was processed by mixing $10 \mu \mathrm{l}$ from OneStep 2X RT-qPCR Master Mix buffer and $2 \mu \mathrm{l}$ from COVID-19 Primer \& Probe Mix oasig ${ }^{\mathrm{TM}}$ buffer in accordance to the Primerdesign coronavirus COVID-19 genesig ${ }^{\circledR}$ Real-Time PCR assay kit (Varelas S.A.). The oligonucleotide primers and probe for the detection of SARS-CoV-2 were selected from the orf $1 \mathrm{ab}$ genome region (the exact sequence of primers is a proprietary right of the company). As a result, a total volume of $20 \mu \mathrm{l}$ was used per reaction and 45 cycles of RT-qualitative PCR reaction were applied.

The RT-qPCR method is based on TaqMan technology by detecting two fluorophores the FAM and HEX fluorophore. The FAM marked probe is designed for a specific region on Sars-CoV 2 RNA and the HEX marked probe is designed for the IC, an artificial gene template. The probes are labeled with fluorescent reporter and quencher dyes so as their hybridization on the sequence of interest report us the existence of the desired sequence.

The results at the end of this procedure were validated as positives, when signal in FAM and HEX channel was reported. Otherwise, when the signal was detected in HEX channel only, the results were considered negatives. For the validation of this procedure a positive marker was used.

Statistical analysis methods (e.g., $2^{-\Delta \Delta \mathrm{Cq}}$ ) were not feasible herein (due to the small sampling of participants). In four cases, spontaneous delivery occurred and in the remaining cases, cesarean section was performed. According to the literature, cesarean section should be reserved for obstetrical indications (113-117). No case of neonatal infection with SARS-COV-2 has yet been documented in Greece, at least to the best of our knowledge. Concerning placental pathology in 
Table III. Placental pathological and clinical findings in COVID-19-positive mothers.

\begin{tabular}{rlcll}
\hline No. & \multicolumn{1}{c}{ Pathological findings } & Case no. ${ }^{\text {a }}$ & \multicolumn{1}{c}{ Clinical findings } & \multicolumn{1}{c}{ Labor modus } \\
\hline 1 & Maternal vascular malperfusion & $9 / 14$ & Moderate fever, mild cough & Spontaneous delivery \\
2 & Decidual arteriopathy/atherosis & $8 / 14$ & Moderate fever, mild cough & Cesarean section \\
3 & Fibrinoid necrosis & $11 / 14$ & Moderate fever, mild cough & Cesarean section \\
4 & Mural hypertrophy of the arterioles of the membranes & $8 / 14$ & Moderate fever, mild cough & Spontaneous delivery \\
5 & Oligohydramnios & $5 / 14$ & Moderate fever, mild cough & Cesarean section \\
6 & Massive chronic histolytic intervillositis & $6 / 14$ & Moderate fever, mild cough & Cesarean section \\
7 & Deciduitis & $14 / 14$ & Moderate fever, mild cough & Spontaneous delivery \\
8 & Delayed chronic villous maturation & $10 / 14$ & Moderate fever, mild cough & Cesarean section \\
9 & Vascular thrombosis & $12 / 14$ & Moderate fever, mild cough & Cesarean section \\
10 & Acute chorioamnionitis & $13 / 14$ & Moderate fever, mild cough & Cesarean section \\
11 & Acute funisitis & $12 / 14$ & Moderate fever, mild cough & Cesarean section \\
12 & Massive fibrin deposition & $13 / 14$ & Moderate fever, mild cough & Cesarean section \\
13 & Intramural fibrin deposition & $12 / 14$ & Moderate fever, mild cough & Spontaneous delivery \\
14 & Avascular villi & $8 / 14$ & Moderate fever, mild cough & Cesarean section \\
\hline
\end{tabular}

aThere were a total of 14 cases; 'Case' does not represent the no. of cases with reported clinical symptoms; the number represents the chronological order in which the case presented to the authors' department, commencing from June, 2020 until January, 2021.

SARS-CoV-2 infection, the most common findings observed in the cases herein were an increased rate of maternal vascular malperfusion, most commonly decidual arteriopathy, including atherosis and fibrinoid necrosis and mural hypertrophy of the arterioles of the membranes. In addition, maternal vascular malperfusion was noted, associated with restrictions of fetal growth in three infants (five pre-term infants and one case of stillbirth due to central placental abruption and oligohydramnios). Gestational hypertension and pre-eclampsia of the mother, as well as other hypertensive disorders were the major risk factors for the observed intrauterine growth restrictions. Other lesions in the pregnant women in the present study with COVID-19 were massive chronic histolytic intervillositis, deciduitis with the presence of lymphocytes and plasma cells, delayed chronic villous maturation, vascular thrombosis, acute chorioamnionitis and funisitis. The pregnant women described herein presented with mild symptoms or were completely asymptomatic with no presence of pneumonia. The authors consider that by providing data regarding their own experience and through the present review article, useful information may be provided for practicing clinicians in order to better understand the impact of SARS-CoV-2 on pregnancy. The current sample size of pregnant women was small. Nevertheless, the results regarding the clinical manifestations are in agreement with those reported in the literature for the majority of pregnant women; i.e., the majority of pregnant women are asymptomatic or have mild symptoms, while in rare cases, a complicated course is observed. One should be aware that COVID-19 infection in pregnant women can lead to severe disease (118-122). Furthermore, the placental pathology findings of the parturient women in the present study are also in agreement with those reported in the literature (114). The authors believe that a strong point of the present narrative review is that it is succinct, yet informative, while a study limitation is the small sample size of pregnant women.

\section{Conclusion and future perspectives}

The elucidation of interactions between pathogen and host at the molecular level will bring valuable information regarding the mechanisms causing adverse disease in pregnant women infected with SARS-CoV-2. In addition, further data are required regarding the optimal management of pregnant women with asymptomatic and symptomatic COVID-19 infection. Currently, corticosteroids (prednisolone or hydrocortisone) and the antiviral drug, remdesivir, are used in pregnant women when they require oxygen alongside antithrombotic prophylaxis. As regards the use of remdesivir, the guidelines suggest not to withhold its use, unless otherwise indicated $(116,117)$, while others suggest that its fetal safety profile is largely unknown (116). Preliminary data for vaccination against SARS-CoV-2 demonstrate no increase in adverse perinatal outcomes (117-124). In addition, no assessment can be made at present regarding the long-term consequences when infection occurs in pregnant women. Therefore, further larger and high-quality designed studies are required, as well as transnational studies in order to monitor and evaluate the postpartum organic and psychological management of mothers and their children.

\section{Acknowledgements}

Not applicable.

\section{Funding}

No funding was received.

\section{Availability of data and materials}

The datasets used and/or analyzed during the current study are available from the corresponding author on reasonable request. 


\section{Authors' contributions}

PT wrote the manuscript. VK, AG, EK XV, AC, KN, AA and $\mathrm{PP}$ assisted in the literature search. MP performed the diagnostic tests for the patients. SZ, AB, GI and FG revised the manuscript. ML performed the histopathological placenta examinations. SM assisted in the preparation of the tables and figures. NN and PR were involved in the conception and design of the study, supervised the study. PT and PR confirm the authenticity of the raw data. All authors who have participated in the work take responsibility for the manuscript which they have read and approved.

\section{Ethics approval and consent to participate}

The pregnant women who participated in the study provided written informed consent in the majority of cases, and oral consent in emergency cases, indicating that they agreed to the use of their samples for scientific research. Participants provide a document proving that patient consent for participation was obtained at the time of the study. Ethical approval for the study was provided by the Ethics Committee of the University Hospital in Alexandroupolis, Democritus University of Thrace (Alexandroupolis, Greece; reference no. 42398/07/10/21).

\section{Patient consent for publication}

Not applicable.

\section{Competing interests}

The authors declare that they have no competing interests.

\section{References}

1. WHO: Rolling updates on coronavirus disease (COVID-19), 2020. https://www.who.int/emergencies/diseases/novelcoronavirus-2019/events-as-they-happen.

2. WHO: Coronavirus disease (COVID-19) outbreak situation, 2020. https://www.who.int/emergencies/diseases/novel-coronavirus-2019.

3. FIGO: Safe motherhood and COVID-19, 2020. https://www.figo. org/safe-motherhood-and-covid-19; https://www.figo.org/sites/ default/files/2020-04/30.03.20\%20-\%20FIGO\%20Statement $\%$ 20 on $\% 20$ Safe $\% 20$ Motherhood\%20and\%20COVID-19\%20EN pdf.

4. RCOG: Coronavirus (COVID-19) infection in pregnancy, 2020. https://www.rcog.org.uk/en/guidelines-research-services/ guidelines/coronavirus-pregnancy/covid-19-virus-infection-andpregnancy/.

5. ACOG: Novel coronavirus 2019 (COVID-19), 2020. https://www. acog.org/clinical/clinical-guidance/practice-advisory/articles/ 2020/03/novel-coronavirus-2019.

6. ACOG: Outpatient assessment and management for pregnant women with suspected or confirmed novel coronavirus (COVID-19), 2020. https://www.acog.org/media/ project/acog/acogorg/files/pdfs/clinicalguidance/practice-advisory/ covid-19-algorithm.pdf?la=en\& hash=2D9E7F62C97F82315616 16FFDCA3B1 A6.

7. Centers for Disease Control and Prevention: Breastfeeding and caring for newborns if you have COVID-19. https://www.cdc gov/coronavirus/2019-ncov/need-extra-precautions/pregnancybreastfeeding.html. Updated Aug 18, 2021.

8. International Committee on Taxonomy of Viruses Executive Committee: The new scope of virus taxonomy: Partitioning the virosphere into 15 hierarchical ranks. Nat Microbiol 5: 668-674, 2020 .
9. Zhu Z, Lian X, Su X, Wu W, Marraro GA and Zeng Y: From SARS and MERS to COVID-19: A brief summary and comparison of severe acute respiratory infections caused by three highly pathogenic human coronaviruses. Respir Res 21: 224, 2020.

10. Cascella M, Rajnik M, Aleem A, Dulebohn SC and Di Napoli R Features, evaluation and treatment coronavirus (COVID-19). In: StatPearls. StatPearls Publishing, Treasure Island, FL, 2021.

11. Xiao Y: Structural and functional studies on coronavirus non-structural proteins 7/8 and 5. Lübeck, 2013. https://www. zhb.uni-luebeck.de/epubs/ediss1359.pdf.

12. Ashour HM, Elkhatib WF, Rahman MM and Elshabrawy HA: Insights into the recent 2019 novel coronavirus (SARS-CoV-2) in light of past human coronavirus outbreaks. Pathogens 9: 186, 2020.

13. Schoeman D and Fielding BC: Coronavirus envelope protein: Current knowledge. Virol J 16: 69, 2019.

14. Huang Y, Yang C, Xu XF, Xu W and Liu SW: Structural and functional properties of SARS-CoV-2 spike protein: Potential antivirus drug development for COVID-19. Acta Pharmacol Sin 41: 1141-1149, 2020.

15. McBride R, van Zyl M and Fielding BC: The coronavirus nucleocapsid is a multifunctional protein. Viruses 6: 2991-3018, 2014.

16. Hu T, Liu Y, Zhao M, Zhuang Q, Xu L and He Q: A comparison of COVID-19, SARS and MERS. PeerJ 8: e9725, 2020.

17. Nakagawa $S$ and Miyazawa T: Genome evolution of SARS-CoV-2 and its virological characteristics. Inflamm Regen 40: 17, 2020.

18. Shi CS, Nabar NR, Huang NN and Kehrl JH: SARS-coronavirus open reading frame-8b triggers intracellular stress pathways and activates NLRP3 inflammasomes. Cell Death Discov 5: 101, 2019.

19. Örd M, Faustova I and Loog M: The sequence at Spike S1/S2 site enables cleavage by furin and phospho-regulation in SARS-CoV2 but not in SARS-CoV1 or MERS-CoV. Sci Rep 10: 16944, 2020.

20. V'kovski P, Kratzel A, Steiner S, Stalder H and Thiel V: Coronavirus biology and replication: Implications for SARS-CoV-2. Nat Rev Microbiol 19: 155-170, 2021.

21. Petersen E, Koopmans M, Go U, Hamer DH, Petrosillo N, Castelli F, Storgaard M, Al Khalili S and Simonsen L: Comparing SARS-CoV-2 with SARS-CoV and influenza pandemics. Lancet Infect Dis 20: e238-e244, 2020.

22. Guo YR, Cao QD, Hong ZS, Tan YY, Chen SD, Jin HJ, Tan KS Wang DY and Yan Y: The origin, transmission and clinical therapies on coronavirus disease 2019 (COVID-19) outbreak-an update on the status. Mil Med Res 7: 11, 2020.

23. Han Y and Yang H: The transmission and diagnosis of 2019 novel coronavirus infection disease (COVID-19): A Chinese perspective. J Med Virol 92: 639-644, 2020.

24. Cevik M, Tate M, Lloyd O, Maraolo AE, Schafers J and Ho A: SARS-CoV-2, SARS-CoV, and MERS-CoV viral load dynamics, duration of viral shedding, and infectiousness: A systematic review and meta-analysis. Lancet Microbe 2: e13-e22, 2021.

25. Yu IT, Li Y, Wong TW, Tam W, Chan AT, Lee JH, Leung DY and Ho T: Evidence of airborne transmission of the severe acute respiratory syndrome virus. N Engl J Med 350: 1731-1739, 2004.

26. Chafekar A and Fielding BC: MERS-CoV: Understanding the latest human coronavirus threat. Viruses 10: 93, 2018

27. Yeo C, Kaushal S and Yeo D: Enteric involvement of coronaviruses: Is faecal-oral transmission of SARS-CoV-2 possible? Lancet Gastroenterol Hepatol 5: 335-337, 2020.

28. Kumar M, Taki K, Gahlot R, Sharma A and Dhangar K: A chronicle of SARS-CoV-2: Part-I-epidemiology, diagnosis, prognosis, transmission and treatment. Sci Total Environ 734: $139278,2020$.

29. van Doremalen N, Bushmaker T, Morris DH, Holbrook MG, Gamble A, Williamson BN, Tamin A, Harcourt JL, Thornburg NJ, Gerber SI, et al: Aerosol and surface stability of SARS-CoV-2 as compared with SARS-CoV-1. N Engl J Med 382: 1564-1567, 2020.

30. Galbadage T, Peterson BM and Gunasekera RS: Does COVID-19 spread through droplets alone? Front Public Health 8: 163, 2020.

31. Yan Y, Chang L and Wang L: Laboratory testing of SARS-CoV, MERS-CoV, and SARS-CoV-2 (2019-nCoV): Current status, challenges, and countermeasures. Rev Med Virol 30: e2106, 2020.

32. Vivanti AJ, Vauloup-Fellous C, Prevot S, Zupan V, Suffee C, Do Cao J, Benachi A and De Luca D: Transplacental transmission of SARS-CoV-2 infection. Nat Commun 11: 3572, 2020.

33. Lu CW, Liu XF and Jia ZF: 2019-nCoV transmission through the ocular surface must not be ignored. Lancet 395: e39, 2020.

34. Lessler J, Reich NG, Brookmeyer R, Perl TM, Nelson KE and Cummings DA: Incubation periods of acute respiratory viral infections: A systematic review. Lancet Infect Dis 9: 291-300, 2009. 
35. Memish ZA, Perlman S, Van Kerkhove MD and Zumla A: middle east respiratory syndrome. Lancet 395: 1063-1077, 2020.

36. Jiang X, Rayner S and Luo MH: Does SARS-CoV-2 has a longer incubation period than SARS and MERS? J Med Virol 92: 476-478, 2020.

37. Lauer SA, Grantz KH, Bi Q, Jones FK, Zheng Q, Meredith HR, Azman AS, Reich NG and Lessler J: The incubation period of coronavirus disease 2019 (COVID-19) from publicly reported confirmed cases: Estimation and application. Ann Intern Med 172: 577-582, 2020.

38. He W, Yi GY and Zhu Y: Estimation of the basic reproduction number, average incubation time, asymptomatic infection rate, and case fatality rate for COVID-19: Meta-analysis and sensitivity analysis. J Med Virol 92: 2543-2550, 2020.

39. Wassie GT, Azene AG, Bantie GM, Dessie G and Aragaw AM: Incubation period of severe acute respiratory syndrome novel coronavirus 2 that causes coronavirus disease 2019: A systematic review and meta-analysis. Curr Ther Res Clin Exp 93: 100607 , 2020 .

40. Zhu W, Zeng N and Wang N: Sensitivity, specificity, accuracy, associated confidence interval and $\mathrm{ROC}$ analysis with practical SAS $^{\circledR}$ implementations. Health Care and Life Sciences, 2010 https://www.lexjansen.com/nesug/nesug10/hl/hl07.pdf.

41. Li C and Ren L: Recent progress on the diagnosis of 2019 novel coronavirus. Transbound Emerg Dis 67: 1485-1491, 2020.

42. Sethuraman N, Jeremiah SS and Ryo A: Interpreting DIAGNOSTIC Tests for SARS-CoV-2. JAMA 323: 2249-2251, 2020

43. Böger B, Fachi MM, Vilhena RO, Cobre AF, Tonin FS and Pontarolo R: Systematic review with meta-analysis of the accuracy of diagnostic tests for COVID-19. Am J Infect Control 49: 21-29, 2021.

44. Fujisaki S, Mori N, Sasaki T and Maeyama M: Cell-mediated immunity in human pregnancy: Changes in lymphocyte reactivity during pregnancy and postpartum. Microbiol Immunol 23: 899-907, 1979

45. Dashraath P, Wong JLJ, Lim MXK, Lim LM, Li S, Biswas A, Choolani M, Mattar C and Su LL: Coronavirus disease 2019 (COVID-19) pandemic and pregnancy. Am J Obstet Gynecol 222: 521-531, 2020

46. Yu N, Li W, Kang Q, Xiong Z, Wang S, Lin X, Liu Y, Xiao J Liu H, Deng D, et al: Clinical features and obstetric and neonatal outcomes of pregnant patients with COVID-19 in Wuhan, China: A retrospective, single-centre, descriptive study. Lancet Infect Dis 20: 559-564, 2020.

47. Chen L, Li Q, Zheng D, Jiang H, Wei Y, Zou L, Feng L, Xiong G, Sun G, Wang H, et al: Clinical characteristics of pregnant women with Covid-19 in Wuhan, China. N Engl J Med 382: e100, 2020.

48. Elshafeey F, Magdi R, Hindi N, Elshebiny M, Farrag N, Mahdy S, Sabbour M, Gebril S, Nasser M, Kamel M, et al: A systematic scoping review of COVID-19 during pregnancy and childbirth. Int J Gynaecol Obstet 150: 47-52, 2020.

49. Ferrazzi E, Frigerio L, Savasi V, Vergani P, Prefumo F, Barresi S, Bianchi S, Ciriello E, Facchinetti F, Gervasi MT, et al: Vaginal delivery in SARS-CoV-2-infected pregnant women in Northern Italy: A retrospective analysis. BJOG 127: 1116-1121, 2020

50. Kidd P: Th1/Th2 balance: The hypothesis, its limitations, and implications for health and disease. Altern Med Rev 8: 223-246, 2003.

51. Oltean I, Tran J, Lawrence S, Ruschkowski BA, Zeng N, Bardwell C, Nasr Y, de Nanassy J and El Demellawy D Impact of SARS-CoV-2 on the clinical outcomes and placental pathology of pregnant women and their infants: A systematic review. Heliyon 7: e06393, 2021.

52. Berghella V and Hughes BL: COVID-19: Pregnancy issues and antenatal care. Literature review current through. Lockwood C. and Barss VA (eds). 2021.

53. Ramlakhan KP, Johnson MR and Roos-Hesselink JW: Pregnancy and cardiovascular disease. Nat Rev Cardiol 17: 718-731, 2020

54. Chen H, Guo J, Wang C, Luo F, Yu X, Zhang W, Li J, Zhao D, $\mathrm{Xu} \mathrm{D}$, Gong $\mathrm{Q}$, et al: Clinical characteristics and intrauterine vertical transmission potential of COVID-19 infection in nine pregnant women: A retrospective review of medical records. Lancet 395: 809-815, 2020.

55. Ashokka B, Loh MH, Tan CH, Su LL, Young BE, Lye DC, Biswas A, Illanes SE and Choolani M: Care of the pregnant woman with coronavirus disease 2019 in labor and delivery: Anesthesia, emergency cesarean delivery, differential diagnosis in the acutely ill parturient, care of the newborn, and protection of the healthcare personnel. Am J Obstet Gynecol 223: 66-74.e3, 2020.
56. Liu H, Liu F, Li J, Zhang T, Wang D and Lan W: Clinical and CT imaging features of the COVID-19 pneumonia: Focus on pregnant women and children. J Infect 80: e7-e13, 2020.

57. Servante J, Swallow G, Thornton JG, Myers B, Munireddy S, Malinowski AK, Othman M, Li W, O'Donoghue $\mathrm{K}$ and Walker KF: Haemostatic and thrombo-embolic complications in pregnant women with COVID-19: A systematic review and critical analysis. BMC Pregnancy Childbirth 21: 108, 2021.

58. Wu X, Sun R, Chen J, Xie Y, Zhang S and Wang X: Radiological findings and clinical characteristics of pregnant women with COVID-19 pneumonia. Int J Gynaecol Obstet 150: 58-63 2020.

59. RCPI IoOaG: COVID-19 Infection Guidance for Maternity Services. Version 3.0, 2020. https://www.rcpi. ie/news/releases/theinstitute-of-obstetricians-andgynaecologistsissuesguidance-on-covid-19-and-maternityservices/.

60. Di Mascio D, Khalil A, Saccone G, Rizzo G, Buca D, Liberati M, Vecchiet J, Nappi L, Scambia G, Berghella V and D'Antonio F: Outcome of coronavirus spectrum infections (SARS, MERS COVID-19) during pregnancy: A systematic review and meta-analysis. Am J Obstet Gynecol MFM 2: 100107, 2020.

61. Zaigham M and Andersson O: Maternal and perinatal outcomes with COVID-19: A systematic review of 108 pregnancies. Acta Obstet Gynecol Scand 99: 823-829 2020.

62. Karami P, Naghavi M, Feyzi A, Aghamohammadi M, Novin MS, Mobaien A, Qorbanisani M, Karami A and Norooznezhad AH: WITHDRAWN: Mortality of a pregnant patient diagnosed with COVID-19: A case report with clinical, radiological, and histopathological findings. Travel Med Infect Dis: 101665. 2020 (Online ahead of print).

63. Hantoushzadeh S, Shamshirsaz AA, Aleyasin A, Seferovic MD, Aski SK, Arian SE, Pooransari P, Ghotbizadeh F, Aalipour S, Soleimani Z, et al: Maternal death due to COVID-19. Am J Obstet Gynecol 223: 109.e1-109.e16, 2020.

64. Ferrazzi EM, Frigerio L, Cetin I, Vergani P, Spinillo A, Prefumo F, Pellegrini E and Gargantini G: COVID-19 obstetrics task force, Lombardy, Italy: Executive management summary and short report of outcome. Int J Gynaecol Obstet 149: 377-378, 2020.

65. Ronnje L, Länsberg JK, Vikhareva O, Hansson SR, Herbst A and Zaigham M: Complicated COVID-19 in pregnancy: A case report with severe liver and coagulation dysfunction promptly improved by delivery. BMC Pregnancy Childbirth 20: 511, 2020

66. Shanes ED, Mithal LB, Otero S, Azad HA, Miller ES and Goldstein JA: Placental pathology in COVID-19. Am J Clin Pathol 154: 23-32, 2020

67. Juan J, Gil MM, Rong Z, Zhang Y, Yang H and Poon LC: Effect of coronavirus disease 2019 (COVID-19) on maternal, perinatal and neonatal outcome: Systematic review. Ultrasound Obstet Gynecol 56: 15-27, 2020.

68. Diriba K, Awulachew E and Getu E: The effect of coronavirus infection (SARS-CoV-2, MERS-CoV, and SARS-CoV) during pregnancy and the possibility of vertical maternal-fetal transmission: A systematic review and meta-analysis. Eur J Med Res 25: $39,2020$.

69. Kaur N, Singh R, Dar Z, Bijarnia RK, Dhingra N and Kaur T: Genetic comparison among various coronavirus strains for the identification of potential vaccine targets of SARS-CoV2. Infect Genet Evol 89: 104490, 2021.

70. RCOG: Coronavirus (COVID-19) infection in pregnancy information for healthcare professionals. Version 8, 2020. https://www. rcog.org.uk/ globalassets/documents/guidelines/2020-04-17-coro navirus-covid-19-infection-in-pregnancy.pdf.

71. Baud D, Greub G, Favre G, Gengler C, Jaton K, Dubruc E and Pomar L: Second-trimester miscarriage in a pregnant woman with SARS-CoV-2 infection. JAMA 323: 2198-2200, 2020.

72. Aliji N and Aliu F: Oligohydramnion in COVID19. Eur J Obstet Gynecol Reprod Biol 249: 102, 2020.

73. Khan S, Peng L, Siddique R, Nabi G, Nawsherwan, Xue M, Liu J and Han G: Impact of COVID-19 infection on pregnancy outcomes and the risk of maternal-to-neonatal intrapartum transmission of COVID-19 during natural birth. Infect Control Hosp Epidemiol 41: 748-750, 2020.

74. Dennis AT, Hardy L and Leeton L: The prone position in healthy pregnant women and in women with preeclampsia-a pilot study. BMC Pregnancy Childbirth 18: 445, 2018.

75. Akatsuka M, Tatsumi H, Yama N and Masuda Y: Therapeutic evaluation of computed tomography findings for efficacy of prone ventilation in acute respiratory distress syndrome patients with abdominal surgery. J Crit Care Med (Targu Mures) 6: 32-40, 2020 . 
76. Klok FA, Kruip MJHA, van der Meer NJM, Arbous MS, Gommers DAMPJ, Kant KM, Kaptein FHJ, van Paassen J, Stals MAM, Huisman MV and Endeman H: Incidence of thrombotic complications in critically ill ICU patients with COVID-19. Thromb Res 191: 145-147, 2020.

77. Cui S, Chen S, Li X, Liu S and Wang F: Prevalence of venous thromboembolism in patients with severe novel coronavirus pneumonia. J Thromb Haemost 18: 1421-1424, 2020.

78. Tang N, Bai H, Chen X, Gong J, Li D and Sun Z: Anticoagulant treatment is associated with decreased mortality in severe coronavirus disease 2019 patients with coagulopathy. J Thromb Haemost 18: 1094-1099, 2020.

79. Di Renzo GC and Giardina I: Coronavirus disease 2019 in pregnancy: Consider thromboembolic disorders and thromboprophylaxis. Am J Obstet Gynecol 223: 135, 2020.

80. McIntosh JJ: Corticosteroid guidance for pregnancy during COVID-19 pandemic. Am J Perinatol 37: 809-812, 2020.

81. India TFoOGSo: Pregnancy with COVID-19 infection. FOGSI GCPR good clinical practice recommendation. Version 2, 2020. https://www.fogsi.org/the-draft-version1-fogsi_gcpr_on pregnancy_with_covid_19_infection/.

82. Davanzo R, Moro G, Sandri F, Agosti M, Moretti C and Mosca F: Breastfeeding and coronavirus disease-2019: Ad interim indications of the Italian society of neonatology endorsed by the Union of European Neonatal and Perinatal Societies. Matern Child Nutr 16: e13010, 2020.

83. Pascarella G, Strumia A, Piliego C, Bruno F, Del Buono R, Costa F, Scarlata S and Agrò FE: COVID-19 diagnosis and management: A comprehensive review. J Intern Med 288: 192-206, 2020.

84. Gursel $M$ and Gursel I: Is global BCG vaccination-induced trained immunity relevant to the progression of SARS-CoV2 pandemic? Allergy 75: 1815-1819, 2020.

85. Wang M, Cao R, Zhang L, Yang X, Liu J, Xu M, Shi Z, Hu Z, Zhong $\mathrm{W}$ and Xiao G: Remdesivir and chloroquine effectively inhibit the recently emerged novel coronavirus $(2019-\mathrm{nCoV})$ in vitro. Cell Res 30: 269-271, 2020.

86. Gao J, Tian Z and Yang X: Breakthrough: Chloroquine phosphate has shown apparent efficacy in treatment of COVID-19 associated pneumonia in clinical studies. Biosci Trends 14 72-73, 2020.

87. Yao X, Ye F, Zhang M, Cui C, Huang B, Niu P, Liu X, Zhao L, Dong $\mathrm{E}$, Song $\mathrm{C}$, et al: In vitro antiviral activity and projection of optimized dosing design of hydroxychloroquine for the treatment of severe acute respiratory syndrome coronavirus 2 (SARS-CoV-2). Clin Infect Dis 71: 732-739, 2020.

88. Gautret P, Lagier JC, Parola P, Hoang VT, Meddeb L, Mailhe M, Doudier B, Courjon J, Giordanengo V, Vieira VE, et al: Hydroxychloroquine and azithromycin as a treatment of COVID-19: Results of an open-label non-randomized clinical trial. Int J Antimicrob Agents 56: 105949, 2020.

89. Garcia-Cremades M, Solans BP, Hughes E, Ernest JP Wallender E, Aweeka F, Luetkemeyer AF and Savic RM: Optimizing hydroxychloroquine dosing for patients With COVID-19: An integrative modeling approach for effective drug repurposing. Clin Pharmacol Ther 108: 253-263, 2020.

90. Javelot H, El-Hage W, Meyer G, Becker G, Michel B and Hingray C: COVID-19 and (hydroxy)chloroquine-azithromycin combination: Should we take the risk for our patients? Br J Clin Pharmacol 86: 1176-1177, 2020.

91. McCreary EK and Pogue JM: Coronavirus disease 2019 treatment: A review of early and emerging options. Open Forum Infect Dis 7: ofaa105, 2020.

92. Costanzo M, De Giglio MAR and Roviello GN: SARS-CoV-2: Recent reports on antiviral therapies based on lopinavir/ritonavir, darunavir/umifenovir, hydroxychloroquine, remdesivir, favipiravir and other drugs for the treatment of the new Coronavirus. Curr Med Chem 27: 4536-4541, 2020.

93. Cao B, Wang Y, Wen D, Liu W, Wang J, Fan G, Ruan L, Song B, Cai Y, Wei M, et al: A trial of Lopinavir-ritonavir in adults hospitalized with severe Covid-19. N Engl J Med 382: 1787-1799, 2020 .

94. LaCourse SM, John-Stewart G and Adams Waldorf KM: Importance of inclusion of pregnant and breastfeeding women in COVID-19 therapeutic trials. Clin Infect Dis 71: 879-881, 2020

95. Ahn DG, Shin HJ, Kim MH, Lee S, Kim HS, Myoung J, Kim BT and Kim SJ: Current status of epidemiology, diagnosis, therapeutics, and vaccines for novel coronavirus disease 2019 (COVID-19). J Microbiol Biotechnol 30: 313-324, 2020.
96. Ahmed SF, Quadeer AA and McKay MR: Preliminary identification of potential vaccine targets for the COVID-19 coronavirus (SARS-CoV-2) based on SARS-CoV immunological studies. Viruses 12: 254, 2020.

97. Liao J, He X, Gong Q, Yang L, Zhou C and Li J: Analysis of vaginal delivery outcomes among pregnant women in Wuhan, China during the COVID-19 pandemic. Int J Gynaecol Obstet 150: 53-57, 2020.

98. Röhr S, Müller F, Jung F, Apfelbacher C, Seidler A and Riedel-Heller SG: Psychosocial impact of quarantine measures during serious coronavirus outbreaks: A rapid review. Psychiatr Prax 47: 179-189, 2020 (In German).

99. Hiremath P, Suhas Kowshik CS, Manjunath M and Shettar M COVID 19: Impact of lock-down on mental health and tips to overcome. Asian J Psychiatr 51: 102088, 2020.

100. Fatke B, Hölzle P, Frank A and Förstl H: COVID-19 crisis: Early observations on a pandemic's psychiatric problems. Dtsch Med Wochenschr 145: 675-681, 2020 (In German).

101. Rashidi Fakari F and Simbar M: Coronavirus pandemic and worries during pregnancy; a letter to editor. Arch Acad Emerg Med 8: e21, 2020.

102. Bohlken J, Schömig F, Lemke MR, Pumberger M and Riedel-Heller SG: COVID-19 pandemic: Stress experience of healthcare workers-A short current review. Psychiatr Prax 47: 190-197, 2020 (In German).

103. Chew NW, Lee GK, Tan BY, Jing M, Goh Y, Ngiam NJ, Yeo LL, Ahmad A, Ahmed Khan F, Shanmugam GN, et al: A multinational, multicentre study on the psychological outcomes and associated physical symptoms amongst healthcare workers during COVID-19 outbreak. Brain Behav Immun 88: 559-565, 2020.

104. Sun N, Wei L, Shi S, Jiao D, Song R, Ma L, Wang H, Wang C, Wang Z, You Y, et al: A qualitative study on the psychological experience of caregivers of COVID-19 patients. Am J Infect Control 48: 592-598, 2020

105. Vieira PR, Garcia LP and Maciel EL: The increase in domestic violence during the social isolation: What does it reveals? Rev Bras Epidemiol 23: e200033, 2020 (In Portuguese).

106. Usher K, Bhullar N, Durkin J, Gyamfi N and Jackson D: Family violence and COVID-19: Increased vulnerability and reduced options for support. Int J Ment Health Nurs 29: 549-552, 2020.

107. Dmitrieva K: Job Losses Deepen in Pandemic with U.S Tally topping 30 million, 2020. https:// www.bloomberg. com/news/articles/2020-04-30/another3-8-million-in-u-s-filedfor-jobless-benefits-last-week.

108. HSE: Hospital service disruptions and visiting restrictions (COVID-19), 2020. https://www2.hse. ie/services/hospital-service-disruptions/hospital-servicedisruptions-covid19.html.

109. Dore B: Covid-19: Collateral damage of lockdown in India BMJ 369: m1711, 2020.

110. FIGO: Fertility Treatment and COVID-19, 2020. https://www. figo.org/fertility-treatment-andcovid-19.

111. Cannistra SA, Haffty BG and Ballman K: Challenges faced by medical journals during the COVID-19 pandemic. J Clin Oncol 38: 2206-2207, 2020.

112. Bothou M, Tsikouras $P$, Iatrakis $G$, Tsatsaris G, Platanisiotis N, Chatzigianni E, Anthoulaki X and Bothou A: Social and psychological effects of coronavirus disease (COVID-19). Rev Clin Pharmacol Pharmacokinet Int Ed 34: 117-120, 2020.

113. Iatrakis G, Tsikouras $P$ and Nikolettos N: Viral Infections/ SARS-COV-2. Obstetrics/ISBN978-618-84118-3-8 Athens, Greece Desmos DigitaLLKE,P.370. https://service.eudoxus.gr/ search/\#a/id:94645778/0.

114. Girolamo RD, Khalil A, Alameddine S, D'Angelo E, Galliani C, Matarrelli B, Buca D, Liberati M, Rizzo G and D'Antonio F: Placental histopathology after SARS-CoV-2 infection in pregnancy: A systematic review and meta-analysis. Am J Obstet Gynecol MFM 3: 100468, 2021.

115. Di Toro F, Gjoka M, Di Lorenzo G, De Santo D, De Seta F, Maso G Risso FM, Romano F, Wiesenfeld U,Levi-D'Ancona R, et al: Impact of COVID-19 on maternal and neonatal outcomes: A systematic review and meta-analysis. Clin Microbiol Infect 27: 36-46, 2021.

116. Galang RR, Newton SM, Woodworth KR, Griffin I, Oduyebo T, Sancken CL, Olsen EO, Aveni K, Wingate H, Shephard H, et al: Risk factors for illness severity among pregnant women with confirmed severe acute respiratory syndrome coronavirus 2 infection-surveillance for emerging threats to mothers and babies network, 22 state, local, and territorial health departments, 29 March 2020-5 March 2021. Clin Infect Dis 73 (Suppl 1): S17-S23, 2021 
117. NIH: Coronavirus Disease 2019 (COVID-19). Treatment Guidelines. https://www.covid19treatmentguidelines.nih.gov/. Accessed October 1,2021.

118. Shimabukuro TT, Kim SY, Myers TR, Moro PL, Oduyebo T, Panagiotakopoulos L, Marquez PL, Olson CK, Liu R, Chang KT, et al: Preliminary findings of mRNA Covid-19 vaccine safety in pregnant persons. N Engl J Med 384: 2273-2282, 2021.

119. RoyalCollege ofObstetricians andGynaecologists: Coronavirus (COVID-19), pregnancy and women's health.https://www.rcog. org.uk/en/guidelines-research-services/coronavirus-covid-19. pregnancy-and-womens-health/. Accessed October 1, 2021.

120. Wong YP, Khong TY and Tan GC: The effects of COVID-19 on placenta and pregnancy: What do we know so far? Diagnostics (Basel) 11: 94, 2021.

121. Blakeway H, Prasad S, Kalafat E, Heath PT, Ladhani SN Le Doare K, Magee LA, O'brien P, Rezvani A, Dadelszen PV and Khalil A: COVID-19 vaccination during pregnancy: Coverage and safety. Am J Obstet Gynecol: Aug 10, 2021 (Epub ahead of print).

122. Subbaraman N: Pregnancy and COVID: What the data say. Nature 591: 193-195, 2021.
123. Shanes ED, Otero S, Mithal LB, Mupanomunda CA, Miller ES and Goldstein JA: Severe acute respiratory syndrome coronavirus 2 (SARS-CoV-2) vaccination in pregnancy: measures of immunity and placental histopathology. Obstet Gynecol 138: 281-283, 2021.

124. Stafford IA, Parchem JG and Sibai BM: The coronavirus disease 2019 vaccine in pregnancy: Risks, benefits, and recommendations. Am J Obstet Gynecol 224: 484-495, 2021.

125. Dinnes J, Deeks JJ, Berhane S, Taylor M, Adriano A, Davenport C, Dittrich S, Emperador D, Takwoingi Y, Cunningham J, et al: Rapid, point-of-care antigen and molecular-based tests for diagnosis of SARS-CoV-2 infection. Rapid, point-of-care antigen and molecular-based tests for diagnosis of SARS-CoV-2 infection. Cochrane Database Syst Rev: Aug 26, 2020 (Epub ahead of print).

126. Deeks JJ, Dinnes J, Takwoingi Y, Davenport C, Spijker R, Taylor-Phillips S, Adriano A, Beese S, Dretzke J, Ferrante di Ruffano L, et al: Antibody tests for identification of current and past infection with SARS-CoV-2. Cochrane Database Syst Rev: Jun 25, 2020 (Epub ahead of print).

This work is licensed under a Creative Commons Attribution-NonCommercial-NoDerivatives 4.0 International (CC BY-NC-ND 4.0) License. 